\title{
Apontamentos sobre Promoção da Saúde e Biopoder'
}

\section{Notes on Health Promotion and Biopower}

João Leite Ferreira Neto

Doutor em Psicologia Clínica, Professor do Programa de Mestrado em Psicologia (PUC-Minas).

Endereço: Rua Planetoides, 271/102, Santa Lúcia, CEP 30360-440, Belo Horizonte, MG, Brasil.

E-mail: jleite.bheœterra.com.br

\section{Luciana Kind}

Doutora em Saúde Coletiva, Professora do Curso de Psicologia (PUC-Minas).

Endereço: Rua Planetoides, 271/102, Santa Lúcia, CEP 30360-440, Belo Horizonte, MG, Brasil.

E-mail: lukind.œgmail.com

\section{Jairo Stacanelli Barros}

Mestrando em Psicologia na PUC-Minas, Psicólogo da UFMG Endereço: Rua Cristovão Macedo, 42, Alvorada, CEP 32042-210, Contagem, MG, Brasil.

E-mail: jairostabarrosळbol.com.br

\section{Natália Silva Azevedo}

Acadêmica de Psicologia na PUC Minas. Bolsista de iniciação científica.

Endereço: Av. Cristiano Machado, 1440/104, Sagrada Família, CEP 31140-660, Belo Horizonte, MG, Brasil.

E-mail: nataliazevedoळhotmail.com.br

\section{Tatiane Marques Abrantes}

Acadêmica de Psicologia na PUC Minas. Bolsista de iniciação científica.

Endereço: Rua Desterro de Melo, 89, Providência, CEP 31814-190, Belo Horizonte, MG, Brasil.

E-mail: tatiabrantesळyahoo.com.br

I Apoio: Fundação de Amparo à Pesquisa do Estado de Minas

Gerais - FAPEMIC.

\section{Resumo}

Este trabalho é um estudo bibliográfico-exploratório com o objetivo de problematizar o campo da promoção da saúde, localizando alguns de seus avanços e problemas no debate internacional e em sua configuração no Sistema Único de Saúde (SUS) brasileiro. Recorre, para esse fim, a textos e documentos no campo da promoção da saúde aproximando deles a discussão foucaultiana sobre a ação do biopoder, sobre a vida e as resistências que se manifestam nesse embate. Entende a promoção da saúde como um campo de discursos e práticas, saberes e poderes, atravessado, concomitantemente, por dimensões regulatórias e disciplinares, e por dimensões participativas e emancipatórias; e busca realizar uma "genealogia dos problemas" nessa arena. Analisa o Relatório Lalonde e suas repercussões, comenta as Cartas Internacionais de Promoção da Saúde, aborda o diferencial brasileiro com a presença de forças populares na construção das políticas de saúde. Aponta que o trabalho em promoção da saúde não é feito sem tensões, exigindo contínua atenção e um paciente empenho plural de gestores, técnicos e usuários, em que cada avanço inaugura novos perigos, o que demanda novas ações.

Palavras-chave: Promoção da saúde; Biopoder; SUS; Participação social. 


\section{Abstract}

This work is an exploratory and bibliographic study that aims to analyze the health promotion field, identifying some of its advances and problems in the international debate and in its configuration in the Brazilian Health System (SUS). Thus, it uses texts and documents in the health promotion field in light of the Foucaultian discussion about the effects of biopower on life and the resistances that emerge in this clash. It understands health promotion as a field of discourses and practices, knowledge and powers, simultaneously intersected by regulatory and disciplinary dimensions and by participative and emancipatory dimensions, and tries to make a "genealogy of problems" in this arena. It analyzes the Lalonde Report and its repercussions, comments on the international charters of health promotion, and approaches the Brazilian scenario, marked by the presence of popular forces in the construction of health policies. It indicates that the health promotion work is not performed without tensions, requiring constant attention and a plural and patient effort of managers, technicians and the system's users, in which each advance gives rise to new dangers, calling for new actions.

Keywords: Health Promotion; Biopower; SUS; Social Participation.

\section{Apontamentos sobre Promoção da Saúde e Biopoder}

Eu gostaria de fazer a genealogia dos problemas, das problematizações. Minha opinião é que nem tudo éruim, mas tudo é perigoso, o que não significa exatamente o mesmo que ruim. Se tudo é perigoso, então temos sempre algo a fazer. [...] Acho que a escolha ético-política que devemos fazer a cada dia é determinar qual é o principal perigo. (Michel Foucault)

\section{Introdução}

O campo da saúde tem sido sistematicamente modificado pelas políticas de promoção da saúde e pelos debates que as acompanham. Um de seus aspectos mais importantes é o deslocamento nas políticas de saúde da centralidade da assistência médica para a convocação de todos para a gestão dos cuidados em saúde. Nogueira (2003, p. 179) chega a afirmar que esta "é uma forma de medicina que dispensa a figura do médico", ao mobilizar o conjunto da sociedade para o cuidado privado com o corpo e com a saúde. Outro aspecto de realce é uma compreensão mais ampliada do processo saúde-doença, afastando-se da ênfase no corpo doente na direção de evidenciar determinantes mais plurais, com acento na noção de fatores de risco, diluindo assim as fronteiras entre doentes e supostamente saudáveis.

Recentemente, em 2006, tivemos aprovada a Política Nacional de Promoção da Saúde no Brasil, que nos interessa em particular. 0 documento revela aspectos da dupla dimensão da promoção da saúde apontada por Carvalho (2004). 0 autor pondera que a avaliação política das propostas de promoção da saúde apresenta dois posicionamentos centrais. 0 primeiro afirma 0 caráter progressista, considerando que o projeto da Nova Promoção da Saúde "representa um esforço de atualização dos compromissos com o bem comum, a equidade social e os princípios democráticos da 'tradição' da Saúde Pública” (Carvalho, 2004, p. 671). 0 segundo considera que os discursos da promoção da saúde refletem a ótica das formações neoliberais, individualistas, voltado para a regulação e a vigilância.

Sobre esse segundo aspecto, o autor cita Castiel (2004), que faz uma distinção entre as estratégias 
políticas que fundamentam as ações de promoção da saúde, mencionando que podem ser aí identificadas posturas conservadoras ou "radicais libertárias". A primeira enfatizaria o direcionamento dos indivíduos para a autorresponsabilização por sua saúde. A tentativa nessa postura política, para Castiel, é a redução de custos na assistência em saúde. Na via reformista, o objetivo é mudar a relação entre cidadãos e Estado, enfatizando as políticas públicas e a ação intersetorial. A postura conservadora, guiada por abordagens educacionais, emprega modelos instrumentais chamados genericamente pelo autor de "operativos", que tendem a se tornar prescritivos. 0 autor alerta que há "uma falta de teoria unificada para a promoção de saúde" (Castiel, 2004, p. 617).

Sem a pretensão de encontrar tal ponto de unificação entre as distintas posições nos debates sobre promoção da saúde, nossa análise tenta transformar a dicotomia sinalizada pelos autores mencionados em uma bipolaridade, entendendo que esse campo não tem um caráter substancial, mas é marcado por polaridades de forças, tensões. Pretende-se ressaltar uma "lógica de campo" e não uma "lógica de substância" (Agamben, 2006, p. 133). Trata-se, portanto, de pensar a promoção da saúde como um campo de discursos e práticas, saberes e poderes, atravessado, concomitantemente, por dimensões regulatórias e disciplinares, e dimensões participativas e emancipatórias, visando realizar uma "genealogia dos problemas" que atravessam esses diversos âmbitos. Nossa hipótese é a de que analisar este campo com base em categorias dicotômicas, tais como clínica $\times$ política, psicológico × comunitário, individual $\times$ coletivo, regulamentação $\times$ autonomia, pode obscurecer a apreensão mais acurada do que acontece nas práticas de promoção da saúde em curso. As últimas duas dicotomias serão particularmente desconstruídas através da análise do debate internacional e da experiência brasileira. A perspectiva de trabalhar essas categorias de modo articulado é um dos temas apontados na atual Política Nacional de Promoção da Saúde.

A reflexão sobre promoção da saúde que intentamos realizar neste texto deriva de uma pesquisa sobre as práticas de grupo como estratégia de intervenção em saúde. Este estudo, de caráter bibliográfico-exploratório, tem por objetivo problematizar o campo da promoção da saúde, localizando alguns de seus avanços e problemas no debate internacional e em sua configuração no Sistema Único de Saúde (SUS) brasileiro. A noção foucaultiana de biopoder será utilizada como instrumento para problematizar a discursividade da promoção da saúde. O discurso é aqui entendido, conforme Foucault o define, como "um bem que coloca desde sua existência a questão do poder, um bem que é, por natureza, objeto de uma luta, e de uma luta política" (Foucault, 1987, p. 139). 0 enunciado discursivo possui um regime de materialidade institucional e sua análise deve ir além da exegese textual, incluindo as condições sócio-institucionais de sua produção.

0 trabalho também se dedica a identificar elementos regulamentadores e disciplinadores presentes nos enunciados sobre esse tema, e indicar as possibilidades libertárias de que as propostas de promoção da saúde são portadoras, entendendo que esses processos aparecem, quase sempre, entrelaçados. Recorremos, para esse fim, a textos e documentos no campo da promoção da saúde aproximando deles a discussão foucaultiana sobre biopoder. Ao abordar o campo da promoção da saúde como constituído por polaridades de forças e tensões, cujo resultado não pode ser decidido previamente, este trabalho aposta na importância de pesquisas que analisem as variadas formas de composição tomadas pelas práticas de promoção da saúde em diferentes contextos, identificando, assim, tanto as forças de submetimento e padronização, quanto as forças emancipatórias de participação inventiva e autônoma.

\section{Biopoder: a vida tomada como objeto político}

Foucault propõe a hipótese de que houve uma transformação a partir da época clássica, em que o direito do soberano de fazer morrer dava lugar a um poder que gera e ordena a vida. Assim, "o direito de causar a morte ou deixar viver foi substituído por um direito de causar a vida" (Foucault, 1988, p. 130). Esse poder sobre a vida, o biopoder, desenvolveu-se nos séculos XVII e XVIII, portando dois polos: o primeiro referente a uma disciplina anátomo-política dos corpos individuais e o segundo marcado por uma regulação biopolítica da população (natalidade e mortalidade, saúde, demografia, circulação de riquezas). É importante demarcar que a noção de biopolítica foi inicialmente construída em 
seus estudos sobre "O nascimento da medicina social", como estratégia que define a medicina na Europa do século XVIII, em sua função de higiene pública que tem nova tarefa. Na aula de 17 de março de 1976, em parte do curso "Em defesa da sociedade", ministrado no Collège de France, Foucault aprofunda essa noção ao discutir o biopoder. Ele aponta a emergência, no final do século XVII, de uma medicina que tem por "função maior a higiene pública, com organismos de coordenação dos tratamentos médicos, de centralização da informação, de normalização do saber, e que adquire também o aspecto de campanha de aprendizado da higiene e de medicalização da população" (Foucault, 2000, p. 291).

As técnicas de poder estavam presentes por todo o corpo social em instituições bem diversas, estatais ou paraestatais (família, Exército, escola, polícia, medicina, entre outras). Elas também são historicamente variáveis e por isso Foucault desenvolve uma análise precisa e específica. Por exemplo, na Alemanha do século XVIII, a medicina de Estado envolveu a construção de um sistema estatal de observação da morbidade solicitada aos hospitais e aos médicos; a normalização da prática e do saber médicos a cargo da universidade e da própria corporação; sistema administrativo para controle das atividades médicas e contratação dos mesmos pelo governo com responsabilidade distrital. $\mathrm{Na}$ França, no final do mesmo século, a medicina urbana promoveu o aperfeiçoamento da quarentena medieval através de um esquadrinhamento de vigilância da cidade, com registro e inspetoria diários, controle dos espaços de perigo sanitário, especialmente os cemitérios, e intervenções na arquitetura urbana com abertura de grandes avenidas visando arejamento. Na Inglaterra do século XIX, a medicina da força de trabalho, promovida devido à industrialização e ao surgimento do proletariado, possibilitou o aparecimento de práticas de assistência médica à pobreza como estratégia de evitar epidemias dessa origem, além das campanhas de vacinação. Era ainda uma medicina do ambiente e dos efeitos do ambiente sobre o organismo, antes de se tornar, na segunda metade do século XIX, uma medicina do organismo (Foucault, 1979). Em resumo, diferentes contextos produziram diferentes conjuntos de saberes e poderes como técnicas de dominação.

Contudo, ainda acompanhando o pensamento de
Foucault (1988, p. 134), a gestão da vida através de técnicas de dominação não se dá de forma total; a vida "escapa continuamente". Existem "as forças que resistem" (1988, p. 266), pois as resistências nunca se encontram em posição de exterioridade em relação ao poder. Por essa razão, a analítica foucaultiana trabalha com a noção de um campo de forças móvel e transitório, que deve ser compreendido em sua processualidade. As forças que resistem se apoiarão naquilo que o poder investe: a vida, entendida como as necessidades fundamentais (corpo, saúde, felicidade, necessidades fundamentais). 0 conceito de resistência tem uma longa trajetória na obra de Foucault, em sua preocupação permanente de pautar os lugares de enfrentamento das práticas de dominação. Do livro inaugural sobre a História da Loucura, quando ele localiza na literatura trágica os aspectos de produção inventiva, ao livro sobre a História da Sexualidade II, em que a resistência aparece tematizada como liberdade/autonomia/invenção a partir da noção de "artes da existência" (Ferreira Neto, 2007). Neste nosso estudo, limitaremos a análise dessa noção tal como ele desenvolveu nos anos 1970 nos textos já mencionados.

Ainda que, por vezes, Foucault seja visto como um teórico do confinamento, das relações de poder e dominação, da denúncia das falsas liberdades que a sociedade disciplinar do capitalismo hodierno propõe, nos últimos anos de sua produção o tema da liberdade tem uma presença vigorosa. No entanto, liberdade em Foucault não tem um sentido fundacionista. Ela reside na aposta de que a experiência historicamente constituída não está sob a égide da determinação necessária, mas da contingência. Suas análises contrapõem-se "à ideia de necessidades universais na existência humana [...] acentuam o caráter arbitrário das instituições e nos mostram de que espaço de liberdade ainda dispomos" (Foucault, 2004, p. 296). Por isso, a liberdade é definida como sendo uma prática ético-política de invenção de novos modos de subjetivação, novas formas de coexistência. Essa invenção não se dá de modo descontextualizado, ela é produzida no enfrentamento de estados de dominação específicos. Ou seja, a liberdade se constrói como contraposição a processos de dominação historicamente definidos. É o que intentaremos apontar na sequência, ao abordarmos os debates sobre promoção da saúde. 


\section{Promoção da Saúde: elementos do debate internacional}

A primeira menção à ideia da promoção da saúde foi feita pelo sanitarista Henry Sigerist, no início do século XX. Westphal (2006, p. 640) afirma que já estava presente nessa primeira formulação o significado de promoção da saúde como "ações de Educação em Saúde e [...] ações estruturais do Estado para melhorar as condições de vida”. Apesar dessa denominação ter emergido no século passado, encontramos antecedentes de tentativas de "melhoria das condições de vida" desde a cultura grega clássica, que construiu um conjunto de "práticas de si", inspiradas pela filosofia e pela medicina (Foucault, 1984) a ser observada pelo homem da pólis. Entretanto, o debate contemporâneo sobre promoção da saúde emergiu na década de 1970, a partir do Relatório Lalonde (1981/1974), documento de trabalho do Ministério da Saúde do Canadá. Seu objetivo central era o enfrentamento dos custos crescentes de assistência médica, não acompanhados pela resolutividade na atenção médico-centrada, particularmente no caso das doenças crônicas (Buss, 200o). Por conseguinte, a busca de uma racionalidade econômica marcou sua elaboração. 0 diferencial desse momento é propor a promoção da saúde dentro de uma estratégia global para a organização dos serviços de saúde.

O documento definia o campo da saúde como composto por quatro determinantes: biologia humana, ambiente (natural e social), estilo de vida e organização da assistência à saúde. Apontava também que, enquanto a sociedade canadense concentrava seus esforços e recursos, $7 \%$ da riqueza nacional, essencialmente na organização da assistência médica, as causas maiores da morbidade e mortalidade eram provenientes dos outros três fatores: biologia, meio ambiente e estilo de vida (Lalonde, 1981). Ainda que destacasse uma pluralidade de determinantes, a maior parte das ações geradas por esse relatório foi orientada para intervenção sobre os "estilos de vida" dos indivíduos. Sobre esse aspecto, o Relatório adverte que "Decisões e hábitos pessoais que são ruins, do ponto de vista da saúde, criam riscos autoimpostos" (Lalonde, 1981, p. 32). Dessa maneira, o estilo de vida que gera adoecimento ou morte, seria uma contribuição da própria vítima para seu adoecimento ou falecimento. Com isso, os indivíduos passam a ser instados a desenvolver procedimentos de autovi- gilância e práticas autodisciplinares. Na formulação de Foucault, tais práticas estabelecem "o imperativo da saúde: dever de cada um e objetivo de todos" (Foucault, 1979, p. 197).

Observamos que a problematização inicialmente pluralista dos quatro determinantes sobre a saúde pública acabou gerando ações centradas na mudança dos estilos de vida, produzindo, assim, um processo de culpabilização dos pacientes (blaming the victims), com a consequente despolitização do problema, uma vez que o Estado, através dessa ênfase unilateral sobre os estilos de vida, joga para o nível individual processos que têm um contorno sociopolítico mais ampliado. Isso gerou um grande número de críticas por parte de estudiosos e pesquisadores (Lupton, 1995; Carvalho, 2005). De fato, os efeitos práticos das estratégias canadenses pós-Lalonde indicavam um aproveitamento melhor nos setores mais bem situados socialmente e "um efeito menor, e até mesmo negativo, por parte dos setores marginalizados" (Carvalho, 2004, p. 670). Afinal, estilos de vida estão diretamente relacionados com condições de vida.

Alguns anos depois da publicação do Relatório, em 1981, ocorreu no Canadá a Primeira Conferência Nacional de Saúde que buscou equilibrar as ações acentuando a importância do contexto social na determinação do processo saúde-doença, reconhecendo a dependência do estilo de vida ao pertencimento a uma dada classe social (Ferreira e Buss, 2001).

Preocupado com os rumos atuais do biopoder na saúde e com a expansão da jurisdição médica além do tratamento de doenças, Rose (2007, p. 10) alerta para a ocorrência de um deslocamento "para a gestão das enfermidades crônicas e morte, a administração da reprodução, a avaliação e gestão do 'risco' e a manutenção e otimização do corpo saudável". Segundo o autor, o campo das biopolíticas iniciado no século XVIII tomou no final do século XX outra configuração. Tratase, agora, de focar menos na doença e mais em nossas capacidades de gerenciar, remodelar e modular as capacidades vitais das pessoas, enfim, de promover uma "política da vida" (politics of life itself). Esse processo incide sobre a promoção da saúde de modo marcante, pois, concordando com o autor,

"Temos visto uma intensificação e generalização das estratégias de promoção da saúde desenvolvidas no século XX juntamente com o aumento da 
indústria de seguro saúde privada, acentuando as obrigações que indivíduos e famílias têm de monitorar e administrar sua própria saúde. Agora cada cidadão precisa tornar-se um ativo parceiro na condução da saúde, aceitando sua responsabilidade de garantir seu próprio bem-estar" (Rose, 2007, p. 63).

Vemos, portanto, que o autocuidado aparece como elemento disciplinar cada vez mais enfatizado tanto nos programas de saúde pública, quanto nas orientações oriundas da saúde privada. "Perca peso", "evite a gordura”, "deixe de fumar", "pratique sexo seguro", "faça exercícios físicos”, são algumas das palavras de ordem que inflacionam nosso cotidiano e perpassam as políticas de promoção da saúde como uma espécie de herança da ênfase no estilo de vida saudável presente no Relatório Lalonde, configurando um deslocamento do corpo doente para o "corpo espécie" de todos.

Não obstante, Rose aponta que a convocação da responsabilidade individual da saúde não pode ser computada somente como ação de culpabilização dos indivíduos e de despolitização. Essa nova ênfase traz, também, consigo um novo "campo de escolha, prudência e responsabilidade. Isto se abre para a experimentação e a contestação" (2007, p. 76), uma lógica de campo onde se apresentam novas polaridades de poderes e resistências. Como as tecnologias biomédicas possibilitam intervenções em vários níveis da vida humana, nós somos convocados a deliberar sobre questões éticas e políticas em todos esses níveis. Em concordância com Foucault, o autor lembra que, se por um lado novas formas de biopoder se apresentam na gestão tecnológica da saúde, por outro, as "políticas da vida" colocam, inevitavelmente, questões para todos, individual e coletivamente. Em suma, mesmo a vivência individual pode ter uma face de resistência política relevante. Não se trata, portanto, de diferenciar a priori o nível individual como potencialmente reacionário e o coletivo como potencialmente libertário, mas desenvolver análises que apontem, em cada nível, tanto as forças conservadoras quanto as forças emancipatórias.

Além das críticas ao destaque dado ao estilo de vida, outro elemento fortemente rechaçado do Relatório Lalonde foi o fato de preconizar um conjunto de intervenções em torno de temas como o tabagismo, o alcoolismo, as drogas, os exercícios físicos e o lazer, os hábitos alimentares, estabelecendo, assim, uma modelização universalizante de condutas, produzindo, com isso, uma "nova moralidade" coletiva (Petersen e Lupton, 1996). Nas palavras de Pasche e Hennington (1996, p. 34), a ênfase nesses aspectos provoca uma "modelização do comportamento em nome do discurso da saúde e da qualidade de vida".

Apesar das críticas mencionadas, alguns dos conceitos do Relatório Lalonde, tais como "campo da saúde", "estilo de vida" e "qualidade de vida", alimentaram vários debates profícuos na promoção da saúde (1981).

Vemos, portanto, que a noção contemporânea de promoção da saúde emergiu comportando polêmicas. Como nos lembra Foucault (1979, p. 18), o começo histórico das coisas não é "a identidade preservada da origem - é a discórdia entre as coisas, o disparate". Essa discórdia presente na análise das propostas de promoção abre uma gama variada de interpretações de suas estratégias políticas.

Em 1986, em Otawa, a Primeira Conferência Internacional sobre Promoção da Saúde veio também balancear o enfoque individualista da promoção, acentuando seus componentes comunitários, propondo a seguinte definição: "Promoção da saúde é o nome dado ao processo de capacitação da comunidade para atuar na melhoria de sua qualidade de vida e saúde, incluindo uma maior participação no controle deste processo" (Brasil, 2001, p. 11).

Curiosamente, essa Conferência, como aponta Carvalho (2005, p. 63), teve pouca participação de usuários e grupos comunitários, sendo "patrocinada, sobretudo, pela tecnoburocracia estatal, por profissionais da área, dirigentes sanitários e acadêmicos”. Esse é um dos elementos mais problemáticos na análise política da promoção da saúde. Por um lado, sua discursividade assemelha-se à de outros movimentos sociais, numa retórica que desafia a regulação do Estado. Mas, por outro lado, suas origens residem no Estado na gestão da saúde pública, "ao invés de desafiarem diretamente o Estado" (Lupton, 1995, p. 61), como os demais movimentos sociais. Podemos entender com isso que apenas o ideário portador de intenções emancipatórias não assegura às práticas de promoção um caráter inequivocamente libertário. A correção bem intencionada das cartas das Conferências Internacionais de Promoção da Saúde, bem como sua adequada interpretação, não 
constitui uma garantia definitiva da direção ético-política das ações feitas em seu nome, uma vez que esse conjunto de forças sociais possui uma composição diversificada. A promoção da saúde como política pública caminha num certo fio da navalha. Se, por um lado, deve garantir a função regulatória do Estado na gestão de seu sistema de saúde, por outro, deve permitir e incentivar espaços e ações de autonomia e empoderamento individual e coletivo. É esse o permanente esforço de construção de políticas de promoção da saúde feitas em nosso País, cujo sistema de saúde foi gestado na efervescência dos movimentos sociais de base acadêmica e popular.

\section{Promoção de Saúde e SUS}

O SUS tem sua origem em uma confluência de movimentos sociais, que emergem na segunda metade da década de 1970 durante o regime militar que comandava o País, e se formalizou através do aparato legal na nova constituição promulgada em 1988. A grande marca da Reforma Sanitária brasileira, inscrita num contexto de várias frentes de lutas pelas liberdades democráticas, foi encarar a saúde como tema político, produzindo uma "percepção social da saúde como direito de cidadania” (Luz, 1994, p. 136).

Entre as propostas de promoção da saúde e a Construção do SUS, encontramos aproximações e diferenças. Castro e Malo (2006, p. 14) consideram que "SUS e Movimento Internacional de Promoção da Saúde têm princípios sinérgicos”. Podemos perceber essa aproximação desde a elaboração do evento chave da Reforma Sanitária, a $8^{\text {a }}$ Conferência Nacional de Saúde de 1986, que constituiu o ápice da elaboração política e ideológica do projeto da Reforma Sanitária. Contudo, as condições de organização e participação nessa conferência trazem a marca da origem da Reforma brasileira: a participação popular de vários contingentes da sociedade civil. Enquanto as conferências anteriores tinham uma composição fechada com a burocracia estatal e grupos de interesse, a $8^{\text {a }}$ Conferência foi antecedida por amplas discussões em conferências estaduais e municipais e contou com a presença de cerca de quatro mil delegados "de quase todas as forças sociais interessadas na questão da saúde", trazendo consigo "a emergência de novos sujeitos políticos, a liberdade do dissenso e o governo dos cidadãos” (Mendes, 1993, p. 41-42). Além disso, apresentou uma dimensão de resistência, no sentido foucaultiano, tanto ao modelo biomédico e privatista de saúde vigente, quanto à organização autoritária e excludente da sociedade brasileira. Ela foi, portanto, um evento catalisador de vários processos sociais em curso no País, sem o caráter de cúpula dirigente que caracterizou tanto as conferências anteriores, quanto as conferências internacionais de promoção da saúde. Foucault considerava que as forças de resistência se apoiaram na vida tomada como objeto de gestão biopolítica. Por essa razão, a vida se tornou objeto das lutas políticas dos movimentos sociais do século XX: "o direito à vida, ao corpo, à saúde, à felicidade, à satisfação das necessidades [...] foi a réplica política a todos esses novos procedimentos de poder" (Foucault, 1988, p. 136).

As deliberações da $8^{\text {a }}$ Conferência têm algumas afinidades com as conferências internacionais de promoção. Em primeiro lugar, define a saúde como produção social,

“[...] resultante das condições de alimentação, habitação, educação, renda, meio ambiente, trabalho, transporte, emprego, lazer, liberdade, acesso e posse da terra e acesso a serviços de saúde. É assim, antes de tudo, o resultado das formas de organização social da produção, as quais podem gerar grandes desigualdades nos níveis de vida” (Brasil, 1986, p. 4).

Essa definição claramente enfatiza a importância dos aspectos de ambiente (social) e de organização de serviços em detrimento dos aspectos mais individuais da biologia e do estilo de vida propugnados no Relatório Lalonde de 1974. O contexto de transformação sociopolítica do País, que estava em curso, foi indubitavelmente fator determinante para essa direção. Mais importante é enfatizar que, diferentemente das conferências internacionais de promoção da saúde, a $8^{\text {a }}$ Conferência Nacional de Saúde de 1986, o texto constitucional de 1988 e a lei 8.080 de 199o, foram resultantes de processos sociais altamente participativos e plurais, fruto de certo consenso social amplo. Por isso, devem ser analisados a partir de suas condições sócio-institucionais de produção. A percepção da saúde como direito de cidadania politizou o campo da gestão estatal, afastando-o de uma perspectiva meramente técnica ou econômica. 
Vale aqui salientar outro importante aspecto da direção política do movimento sanitário no Brasil. Ao politizar o tema da saúde, investiu-se também na construção de uma base jurídico-legal que amparasse a organização de um Sistema Único de Saúde. Instaurou-se, portanto, na dimensão regulatória um novo campo de embates opondo forças conservadoras e forças libertárias. A assunção constitucional da saúde como "direito de todos e dever do Estado" tornou-se uma alavanca de uma série de avanços posteriores no campo da saúde.

Os movimentos sociais das décadas de 1970 e 1980, até então autônomos em relação ao Estado, sofreram um refluxo na década seguinte e se institucionalizaram, seja através dos conselhos participativos, seja via Organizações não governamentais (ONGs), em parceria com o Estado na gestão das políticas públicas. Ademais, com o advento da Nova República, várias lideranças do movimento sanitário passaram a ocupar cargos de gestão na saúde em níveis federal, estadual e municipal. Nosso cenário atual está assentado em alicerces diferentes do início da Reforma Sanitária, possuindo agora uma base jurídico-formal e administrativa institucionalizada.

Como exemplo das consequências dessas diferenças, podemos aludir à formalização da participação popular na saúde através da criação dos conselhos de saúde. 0 processo de participação autônomo dos movimentos sociais institucionalizados através dos conselhos de saúde, trazendo consigo uma heterogeneidade de modos de funcionamento, com elementos de emancipação e de novas formas de mazelas políticas. Inicialmente podemos apontar que essa modalidade de gestão participativa abre importantes espaços de democracia participativa num cenário de hegemonia da chamada democracia representativa. Junto a isso, observa-se um aumento da dimensão burocrática nos conselhos, submetendo sua agenda às normas do Ministério da Saúde e às resoluções do Conselho Nacional de Saúde, restringindo, assim, seu espaço de autonomia (Stralen, 2005).

Na esteira das ações institucionalizadas, em março de 2006 o Ministério da Saúde aprovou a Política Nacional de Promoção da Saúde, que traz como objetivo "promover a qualidade de vida e reduzir vulnerabilidade e riscos à saúde relacionados aos seus determinantes e condicionantes - modos de viver, condições de trabalho, habitação, ambiente, educação, lazer, cultura, acesso a bens e serviços essenciais" (Brasil, 2006, p. 17). A Política reafirma os preceitos da Carta de Ottawa, acentuando que a "promoção da saúde realiza-se na articulação sujeito/coletivo, público/privado, estado/sociedade, clínica/política, setor sanitário/outros setores [...]" (p. 15). As noções de risco e vulnerabilidade dão a tônica do documento, no qual recomenda-se ações de melhoria das condições de vida da população. A articulação pretendida entre ações individuais e coletivas marca a Política Nacional de Promoção da Saúde como estratégia de biopoder. Cria-se um regime de disciplinarização de comportamentos e condutas individuais - alimentação saudável, exercícios físicos, e assim por diante - articulados a uma regulação biopolítica dessas ações. Ao mesmo tempo, acentua a autonomia e a corresponsabilização individual e coletiva, incluindo o poder público, e fortalecendo a importância da participação social.

Essa direção mais participativa para as ações de saúde aparece de forma contundente na Política Nacional de Promoção da Saúde, como apontamos, como também em gestões municipais. Em Belo Horizonte, o documento que expõe as recomendações para a organização local da assistência básica de saúde também aposta em processos participativos com abordagens de promoção da saúde nos níveis individual, coletivo e comunitário. O documento aposta no vínculo e na lógica do cuidado contínuo para capacitar coletivos e indivíduos para o "reconhecimento e atuação sobre os determinantes de saúde, objetivando uma melhor qualidade de vida" (Belo Horizonte, 20o6, p. 78).

Em reflexão prévia à implantação de uma Política Nacional de Promoção da Saúde, Campos e colaboradores (2004, p. 747) se posicionam a favor do trabalho pela "autonomia de sujeitos e coletividades" de modo a possibilitar que estes "criem normas para suas vidas, formas de lidar com as dificuldades, limites e sofrimentos". Os autores reconhecem que os sujeitos e coletividades no contexto de saúde estão imersos numa "rede de poderes e saberes [...] que libertam e constrangem escolhas", mas insistem na tarefa de se construir

"ações quanto aos modos de vida que apostem na capacidade de autorregulação dos sujeitos sem que isso signifique a retirada das responsabilidades do Estado quanto às condições de vida e, ao mesmo tempo, opere na formulação de legislações que 
dificultem a exposição às situações de risco, reduzindo a vulnerabilidade da população" (Campos e col., 2004, p. 747).

Podemos perceber na condução da Política Nacional de Promoção da Saúde e nos textos e documentos a ela referidos, o esforço de direcionar ações na produção de participação social e autonomia. No entanto, sua origem estatal comporta os impasses próprios da herança de forças sociais hoje institucionalizadas na máquina estatal.

Gastaldo (1997) desenvolveu uma pesquisa abordando o tema da Educação em Saúde no país, parte importante da Promoção da Saúde, a partir do conceito de biopoder. Seu argumento é que a Educação em Saúde não pode ser pensada como algo "bom para todos", mas é uma área de ação significativa do biopoder. Lembra que o século XX conheceu a emergência de um novo paradigma na saúde, mudando seu foco de atenção "da patologia à saúde para todos”, tornando a promoção da saúde um tema cada vez mais relevante.

Em sua revisão dos documentos publicados pelo Ministério da Saúde, percebe uma progressiva mudança de texto mais normativo e autoritário, para a promoção de participação e empowerment comunitário nas atividades da saúde. De 1982 a 1992, a ideia de participação passa a ser referida como chave metodológica para a Educação em Saúde. Esse elemento deve ser entendido não somente como efeito do processo de democratização do Brasil, como igualmente das discussões e diretrizes internacionais da Organização Mundial da Saúde (OMS) e outros órgãos. Entretanto, a autora observa que a implementação dessas propostas participativas carece de efetividade, uma vez que a tática empregada para incentivá-la "não foi nada mais do que 'dizer' aos postos de saúde para adotarem práticas participativas" (Gastaldo, 1997, p. 157). Segundo a autora, faltam laços entre o ideário dos documentos e a capilaridade dos serviços, ainda submetidos à tradição da assistência médico-centrada. Paradoxalmente, nos dados apresentados pela autora, as "forças que resistem" insistem em comparecer e surpreender no cotidiano dos serviços de saúde. Experiências exitosas e inovadoras pululam no cotidiano dos serviços de saúde (Gastaldo, 1997; Ferreira Neto e Kind, 2008).

É importante apontar que seu estudo antecede à implantação em larga escala do Programa de Saúde da Família (PSF) como eixo reorientador do SUS, que a despeito dos vários percalços (Grissotti e Patrício, 2006), tem intensificado os deslocamentos inicialmente preconizados pela promoção da saúde. A portaria que cria os Núcleos de Apoio à Saúde da Família (NASF), aprovada em janeiro de 2008 , com acento nas ações de práticas educativas e formação continuada, fortalece os avanços nessa direção (Brasil, 2008).

\section{Considerações Finais}

A promoção da saúde é uma diretriz construída num contexto primeiro-mundista, em decorrência de uma preocupação com a inelutável tendência de crescimento dos custos com a saúde. Sua proposta de regulação desse processo, através de uma organização do sistema com ênfase na atenção básica e no forte incentivo a estilos de vida saudáveis, produziu novas práticas biopolíticas associadas com práticas disciplinares dos corpos. Contudo, esse foco no corpo individual propiciou, ao mesmo tempo, espaços de resistência e experimentação, com gradientes de invenção e autonomia. Além disso, as Conferências Internacionais posteriores buscaram contrabalançar a ênfase nos estilos de vida com a capacitação comunitária como objetivo fundamental das políticas de saúde.

Ao ser transportado para o Brasil, esse debate encontrou um sistema de saúde produzido no bojo de movimentos sociais com forte participação popular. Houve um encontro com a noção da saúde como produção social e direito de cidadania. A direção escolhida pelo movimento sanitário de construção de um aparato regulatório jurídico como estratégia de luta política, demonstrou que certas regulações politicamente orientadas podem se constituir como espaços para produção de práticas autônomas. Entretanto, esses avanços não podem ser tomados como conquistas definitivas, pois carregam novos perigos advindos do sucesso da própria institucionalização, entre os quais o aumento de processos burocráticos e de controle em detrimento de processos de autonomia e inovação.

Pensar a promoção da saúde no contexto das políticas de saúde exige lidar, concomitantemente, com as dimensões regulatórias, próprias de qualquer política pública, e com as dimensões emancipatórias e de empoderamento individual e comunitário. Como vimos, isso não é feito sem tensões, exigindo contínua atenção e um paciente trabalho plural, de gestores, técnicos e 
usuários, onde cada avanço inaugura novos perigos, o que demanda novas ações. Como nos adverte Foucault, "mas tudo é perigoso, o que não significa exatamente o mesmo que ruim. Se tudo é perigoso, então temos sempre algo a fazer" (Foucault, 1995, p. 256).

\section{Referências}

AGAMBEN, G. Entrevista com Giorgio Agamben. Revista do Departamento de Psicologia - UFF, Rio de Janeiro, v. 18, n. 1, p. 131-6, 2006.

BRASIL. Portaria ${ }^{\circ} 154$ de 24 de janeiro de 2008. Cria os Núcleos de Apoio à Saúde da Família - NASF. Diário Oficial da União, Brasília, DF, 4 mar. 2008. n. 43, Seção 1, p. 38-42.

BRASIL. Ministério da Saúde. Relatório final da $8^{a}$ Conferência Nacional de Saúde. Brasília, 1986. Disponível em: <http://portal.saude.gov.br/portal/ arquivos/pdf/8_CNS_Relatorio\%2oFinal.pdf >. Acesso em: 2 maio 2007.

BRASIL. Ministério da Saúde. Secretaria de Políticas de Saúde. Projeto Promoção da Saúde: as cartas de promoção da saúde. Brasília, 2001.

BRASIL. Ministério da Saúde. Secretaria de Vigilância à Saúde. Secretaria de Atenção à Saúde. Política nacional de promoção da saúde. Brasília, 2006.

BELO HORIZONTE. Secretaria Municipal de Saúde. A gestão básica de saúde em Belo Horizonte: recomendações para a organização local. 2006.

BUSS, P. Promoção da saúde e qualidade de vida. Ciência e Saúde Coletiva, Rio de Janeiro, v. 5, n. 1, p. 163-77, 2000.

CAMPOS, G. S.; BARROS, R. B.; CASTRO, A. M. Avaliação de política nacional de promoção da saúde. Ciência e Saúde Coletiva, Rio de Janeiro, v. 9, n. 3, p. 745-749, jul./set. 2004.

CARVALHO, S. R. As contradições da promoção à saúde em relação à produção de sujeitos e a mudança social. Ciência e Saúde Coletiva, Rio de Janeiro, v. 9, n. 3, p. 669-678, jul./set.2004.

CARVALHO, S. R. Saúde coletiva e promoção da saúde: sujeito e mudanças. São Paulo: Hucitec, 2005.
CASTIEL, L. D. Promoção de saúde e a sensibilidade epistemológica da categoria "comunidade". Revista de Saúde Pública, São Paulo, v. 38, n. 5, p. 615-22, out. 2004.

CASTRO, A.; MALO, M. SUS: resignificando a promoção da saúde. São Paulo: Hucitec/OPAS, 2006.

FERREIRA, J. R.; BUSS, P. Atenção primária e promoção da saúde. In: BRASIL. Ministério da Saúde. Secretaria de Políticas de Saúde. Projeto promoção da saúde: as cartas de promoção da saúde. Brasília, 2001, p. 7-14.

FERREIRA NETO, J. L. Artes da existência: Foucault, a psicanálise e as práticas clínicas. Psicologia: teoria e pesquisa, Brasília, v. 23, n. 2, p 177-83, 2007.

FERREIRA NETO, J. L.; KIND, L. As práticas de grupo como estratégia de intervenção em saúde. [S.l.: s.n.], 2008.

FOUCAULT, M. A arqueologia do saber. 3. ed. Rio de Janeiro: Forense Universitária, 1987.

FOUCAULT, M. Microfísica do poder. Rio de Janeiro: Graal, 1979.

FOUCAULT, M. História da sexualidade I: a vontade de saber. 7. ed. Rio de Janeiro: Graal, 1988.

FOUCAULT, M. História da sexualidade 2: o uso dos prazeres. Rio de Janeiro: Graal, 1984.

FOUCAULT, M. Sobre a genealogia da ética: uma revisão do trabalho. In: DREYFUS, H.; RABINOW, P. Michel Foucault: uma trajetória filosófica. Rio de Janeiro: Forense Universitária, 1995. p. 253-78.

FOUCAULT, M. Em defesa da sociedade. São Paulo: Martins Fontes, 2000.

FOUCAULT, M. Ética, sexualidade, política. Rio de Janeiro: Forense Universitária, 2004. (Coleção Ditos \& Escritos,4).

GASTALDO, D. É a educação em saúde "saudável”? Repensando a educação em saúde através do conceito de biopoder. Educação e realidade, Porto Alegre, v. 22, n. 1, p. 147-167, jan.-jun. 1997.

GRISSOTTI, M.; PATRÍCIO, Z. A saúde coletiva entre discursos e práticas: a participação de usuários, trabalhadores e conselheiros de saúde. Florianópolis: EDSC, 2006. 
LALONDE, M. A new perceptive on the health of

Canadians: a working document. Ottawa: Ministry of Health and Welfare, 1981.

LUPTON, D. The imperative of health: public health and regulated body. London: Sage, 1995.

LUZ, M. T. As conferências nacionais de saúde e as políticas de saúde na década de 8o. In: GUIMARÃES, R.; TAVARES, R. Saúde e sociedade no Brasil: anos 80. Rio de Janeiro: Relume Dumará, 1994. p. 131-52.

MENDES, E. V. As políticas de saúde no Brasil nos anos 80. In: MENDES. E. V. (Org.) Distrito sanitário: o processo de mudança das práticas sanitárias do Sistema Único de Saúde. São Paulo: Hucitec; Rio de Janeiro: Hucitec-Abrasco, 1993. p. 19-91.

NOGUEIRA, R. P. Da medicina preventiva à medicina promotora. In: AROUCA, S. O dilema preventivista: contribuição para a compreensão e crítica da medicina preventiva. São Paulo: Unesp; Rio de Janeiro: Fiocruz, 2003. p. 175-82.
PASCHE, D. F.; HENNINGTON, E. A. O Sistema Único de Saúde e a promoção da saúde. In: CASTRO, A.; MALO, M. SUS: ressignificando a promoção da saúde. São Paulo: Hucitec/OPAS, 2006, p. 19-40.

PETERSEN, A.; LUPTON, D. The new public health: health and self in the age of risk. London: Sage, 1996.

ROSE, N. The politics of life itself: biomedicine, power and subjectivity in the Twenty-First Century. Oxford: Princeton University Press, 2007.

STRALEN, C. J. A gestão participativa de políticas públicas: o caso dos conselhos de saúde. Revista Psicologia Política, Belo Horizonte, v. 2, n. 10, p. 31344, jan.jun. 2005.

WESTPHAL, M. F. Promoção da saúde e prevenção de doenças. In: CAMPOS, G. W. S. et al. (Orgs.). Tratado de saúde coletiva. São Paulo: Hucitec; Rio de Janeiro: Fiocruz, 2006. p. 635-68. 